\title{
Local recurrence following mastectomy and autologous breast reconstruction: incidence, risk factors, and management
}

This article was published in the following Dove Press journal:

OncoTargets and Therapy

4 November 2016

Number of times this article has been viewed

\author{
Siyu $\mathrm{Wu}^{1,2}$ \\ Miao $\mathrm{Mo}^{3}$ \\ Yujie Wang ${ }^{1,2}$ \\ $\mathrm{Na}$ Zhang ${ }^{1,2}$ \\ Jianwei $\mathrm{Li}^{1,2}$ \\ Genhong $\mathrm{Di}^{1,2}$ \\ Zhimin Shao ${ }^{1,2}$ \\ Jiong $\mathrm{Wu}^{1,2}$ \\ Guangyu Liu ${ }^{1,2}$ \\ 'Department of Breast Surgery, Key \\ Laboratory of Breast Cancer in \\ Shanghai, Fudan University Shanghai \\ Cancer Center, ${ }^{2}$ Department of \\ Oncology, Shanghai Medical College, \\ Fudan University, ${ }^{3} \mathrm{Clinical}$ Statistics \\ Center, Fudan University Shanghai \\ Cancer Center, Shanghai, People's \\ Republic of China
}

Correspondence: Guangyu Liu Department of Breast Surgery, Key Laboratory of Breast Cancer in Shanghai, Fudan University Shanghai Cancer Center, No 270, Dongan Road, Shanghai, 200032, People's Republic of China

Tel +862 2I 64175590

Fax +86 2I 64434556

Email liugy123@yahoo.com
Background: Breast reconstruction (BR), including autologous breast reconstruction ( $\mathrm{ABR}$ ) after mastectomy (MST), has been gaining popularity all around the world, especially in the People's Republic of China during the past decade. However, there is a small proportion, but a significant number, of patients who develop local recurrence (LR) of breast cancer postoperatively. The purpose of this study is to examine the incidence of LR, discuss risk factors associated with LR, and management of LR following MST and ABR.

Methods: A total of 397 patients who underwent MST and ABR after diagnosis of breast cancer were included in this retrospective study. Data were analyzed by the Kaplan-Meier method, the log-rank statistical test, and Cox proportional hazards model.

Results: From January 1999 to December 2011, 400 ABRs were performed in 397 patients in Fudan University Shanghai Cancer Center. The median follow-up time in the study was 3.6 years. LR occurred in 11 of 397 patients, with a median time to LR of 2.9 years. In univariate and multivariate analyses, tumor stage, hormonal therapy (yes or no), and tumor type (multifocal or nonmultifocal) were significantly associated with LR after ABR following MST.

Conclusion: ABR is an oncologically safe surgical procedure with an acceptable LR rate of $2.8 \%$. Risk factors associated with high rate of LR were higher tumor stage, absence of hormonal therapy, and multifocal tumor type.

Keywords: local recurrence, autologous breast reconstruction, incidence, risk factors, management

\section{Introduction}

Breast reconstruction (BR), including autologous breast reconstruction (ABR) and prosthesic BR, has increased in incidence during the past decade. There is no doubt that BR greatly minimizes deformity and patients achieve a long-term esthetic result, thus enhancing their psychological well-being after mastectomy (MST). ${ }^{1,2}$ More importantly, BR has been established as an oncologically safe option for not only patients with early breast cancer (BC), ${ }^{3}$ but also advanced BC in the previous studies. ${ }^{4,5}$ However, a small but significant number of patients develop local, regional, or distant recurrence after BR. Therefore, some literature had discussed about locoregional recurrence and distant recurrence after BR. ${ }^{6-8}$ However, few studies reported about local recurrence (LR) after ABR. ${ }^{9}$ The objective of this study was to evaluate incidence of LR following MST and ABR, related risk factors, and management of LR in our institution. Collectively, this study was designed to evaluate a single institution's experience with LR after post-MST BR using autologous flaps, which might be beneficial for the management of this select group of patients in the future. 


\section{Patients and methods}

From January 1999 to June 2014, 860 consecutive BC patients underwent BR in Fudan University Shanghai Cancer Center (FUSCC). Patients were excluded if they had pathological finding of sarcoma/angiosarcoma, phyllodes, inflammatory $\mathrm{BC}$, or they did not undergo MST before BR. Taking at least 3-year follow-up time from December 2014 into account, we identified 397 patients who underwent MST and ABR from January 1999 to December 2011 at FUSCC with a potential follow-up period of more than 36 months. LR was strictly defined as pathologically proven $\mathrm{BC}$ recurring in the ipsilateral chest wall, skin, or subcutaneous tissue overlying the reconstructed breast. In our study, flaps used in ABR consisted of latissimus dorsi, pedicled transverse rectus abdominis myocutaneous flap (pTRAM) and free-TRAM, deep inferior epigastric perforator. None of the cases had MST and immediate tissue expander reconstruction. Whether to perform delayed or immediate, skin-sparing or nipple-sparing BR was left to the surgeon's discretion according to evaluation before or during surgery. The included patients underwent MST and ABR following a diagnosis of BC and all of them achieved negative margins postoperatively. The variables involved in our study included age, estrogen receptor, progesterone receptor (PR), human epidermal growth factor receptor-2 (HER-2), clinical tumor stage, tumor type, tumor grade, lymphovascular invasion status, chemotherapy (CT), radiotherapy (RT), hormonal therapy (HT), pathological tumor size, and number of positive lymph nodes. Among them, tumor type was classified as two types: multifocal tumor and nonmultifocal tumor type; multifocal tumor was defined as Paget's disease or pathologically proven multifocal disease. Both follow-up and LR time was calculated from the time of MST. All the data with regard to patients as well as tumors were obtained from a prospectively maintained institutional database in FUSCC. This study was approved by the independent ethical committee/institutional review board of FUSCC (Shanghai Cancer Center Ethical Committee). Patient consent was not required due to the retrospective nature of the study

Life curve for LR-free survival was calculated using the Kaplan-Meier method. Difference in the survival between two groups was compared by log-rank test in the univariate analysis. Multivariate Cox regression model was applied in the multivariate analysis. LR-free survival was defined as the interval between the date of the operation and LR or the last follow-up. Only factors that turned out significant in univariate analysis could be tested in the multivariate analysis. All the statistics were performed with SPSS 18.0 (SPSS Inc., Chicago, IL, USA). Significance was considered as $P<0.05$.

\section{Results}

From January 1999 to December 2011, there were 397 MST patients who underwent ABR postoperatively. Of 397 patients, three patients presented with simultaneous bilateral $\mathrm{BC}$, so ABRs were performed in 400 breasts of 397 patients during this period. Most breasts were reconstructed using latissimus dorsi flap with or without implant (Table 1). In the entire population, 16 and four cases underwent skin-sparing and nipple-sparing MST, respectively; moreover, only six patients had delayed BR.

\section{Patients and tumor characteristics}

The mean age of all patients at surgery was 39 years (range 19-66 years), most patients were relatively young and therefore not in menopause. Mean size of tumor diameter was $2.7 \mathrm{~cm}$ (range $0.2-13.0 \mathrm{~cm}$ ). All the tumor characteristics are shown in Table 2.

\section{Follow-up and recurrence}

After a median follow-up of 3.6 years, eleven patients presented with LR after ABR. In all the eleven patients with LR, recurrences were first detected by physical examination, which mostly appeared as a palpable mass. Among them, chest wall was the most frequent site of LR (9/11). Besides, one recurrence on the nipple and another in the reconstructed breast were observed. Moreover, more than $50 \%$ of LR events occurred within the first 3 years of MST.

The median time to LR was 2.9 years (range $0.25-4.1$ years). One-, 3-, and 5-year LR-free survival rates for the entire cohort were $99.7 \%, 98.1 \%$, and $95.6 \%$, respectively.

\section{Risk factors and survival}

In univariate analysis, the factors significantly associated with higher LR rate were negative estrogen receptor, multifocal tumor type, absence of HT, and tumor stage III (Figures 1-4). Patients with positive PR as well as post-MST CT tended to have higher LR-free survival compared with those without, but significant difference was not reached $(P>0.05)$.

HT strongly associated with estrogen receptor status, multivariate Cox regression analysis involving HT, tumor

Table I Type of breast reconstructive procedures performed

\begin{tabular}{ll}
\hline Breast reconstruction & $\mathbf{N}(\%)$ \\
\hline LDF with or without implant & $289(72.2)$ \\
PTRAM & $6 I(15.3)$ \\
Free-TRAM/DIEP & $50(12.5)$ \\
\hline
\end{tabular}

Abbreviations: DIEP, deep inferior epigastric perforator; LDF, latissimus dorsi flap; PTRAM, pedicled transverse rectus abdominis myocutaneous; TRAM, transverse rectus abdominis myocutaneous. 
Table 2 Demographic, clinical, and pathological characteristics of patients who underwent autologous breast reconstruction

\begin{tabular}{|c|c|}
\hline Characteristics & $\mathbf{N}(\%)$ \\
\hline Total & $400(100)$ \\
\hline \multicolumn{2}{|l|}{ Age (years) } \\
\hline$\leq 40$ & 235 \\
\hline$>40$ & 165 \\
\hline \multicolumn{2}{|l|}{ cT } \\
\hline TI & 218 \\
\hline $\mathrm{T} 2-4$ & 166 \\
\hline Unknown & 16 \\
\hline \multicolumn{2}{|l|}{$\mathrm{cN}$} \\
\hline No & 328 \\
\hline $\mathrm{NI}-2$ & 72 \\
\hline \multicolumn{2}{|l|}{ Clinical stage } \\
\hline I & 196 \\
\hline II & 183 \\
\hline III & 6 \\
\hline Unknown & 15 \\
\hline \multicolumn{2}{|l|}{ Histological grade } \\
\hline I (IDC) + low (DCIS) & 18 \\
\hline $2($ IDC) + median (DCIS) & 200 \\
\hline $3($ IDC) + high (DCIS) & 100 \\
\hline Other & 19 \\
\hline Unknown & 63 \\
\hline \multicolumn{2}{|l|}{ LVSI } \\
\hline Positive & 121 \\
\hline Negative & 273 \\
\hline Unknown & 6 \\
\hline \multicolumn{2}{|l|}{$\mathrm{p} T$} \\
\hline Tis & 56 \\
\hline $\mathrm{TI}$ & 193 \\
\hline $\mathrm{T} 2$ & 118 \\
\hline T3-4 & 14 \\
\hline Unknown & 19 \\
\hline \multicolumn{2}{|l|}{$\mathrm{pN}$} \\
\hline No & 283 \\
\hline $\mathrm{NI}$ & 82 \\
\hline N2-3 & 35 \\
\hline \multicolumn{2}{|l|}{ ER } \\
\hline Positive & 262 \\
\hline Negative & $|3|$ \\
\hline Unknown & 7 \\
\hline \multicolumn{2}{|l|}{ PR } \\
\hline Positive & 232 \\
\hline Negative & 146 \\
\hline Unknown & 22 \\
\hline \multicolumn{2}{|l|}{ HER2 (FISH) } \\
\hline Positive & 82 \\
\hline Negative & 295 \\
\hline Unknown & 23 \\
\hline \multicolumn{2}{|l|}{ Tumor type } \\
\hline Multifocal disease type & 35 \\
\hline Nonmultifocal disease type & 365 \\
\hline \multicolumn{2}{|l|}{ HT } \\
\hline Yes & 283 \\
\hline No & 111 \\
\hline Unknown & 6 \\
\hline
\end{tabular}

Table 2 (Continued)

\begin{tabular}{ll}
\hline Characteristics & $\mathbf{N}(\%)$ \\
\hline CT & \\
Yes & 311 \\
No & 78 \\
Unknown & 11 \\
RT & \\
Yes & 73 \\
No & 319 \\
Unknown & 8 \\
\hline
\end{tabular}

Abbreviations: $\mathrm{cN}$, clinical $\mathrm{N}$ stage; $\mathrm{cT}$, clinical $\mathrm{T}$ stage; $\mathrm{CT}$, chemotherapy; DCIS, ductal carcinoma in situ; ER, estrogen receptor; HT, hormonal therapy; IDC, invasive ductal carcinoma; LVSI, lymphovascular invasion; PT, pathological T stage; $\mathrm{pN}$, pathological $\mathrm{N}$ stage; PR, progesterone receptor; RT, radiotherapy.

stage, and tumor type showed that HT (hazard ratio $=5.48$, $P<0.05)$, stage III $(P<0.05)$, and multifocal tumor type (hazard ratio $=7.45, P<0.05$ ) were found to be independent risk factors of LR post-MST ABR (Table 3).

\section{Treatment of LR}

Besides first choice of excision of recurrent diseases (8/11), additional treatment included CT (9/11), RT (7/11), HT (5/11), and anti-HER-2 therapy (2/11) according to different situations. Implant/autologous flaps were removed in two of eight surgically treated patients.

\section{Discussion}

With the increasing incidence of $\mathrm{BR}$, more and more reports are paying attention to the recurrence of $\mathrm{BC}$ after $\mathrm{BR}$, including autologous and prosthetic BR. ${ }^{10,11}$ Most of the previous studies focused on TRAM flap reconstruction for its wide acceptance as a standard method for ABR, ${ }^{12-14}$ while ours was one of the few studies to have explored the development of LR of BC after the different kinds of ABRs, which

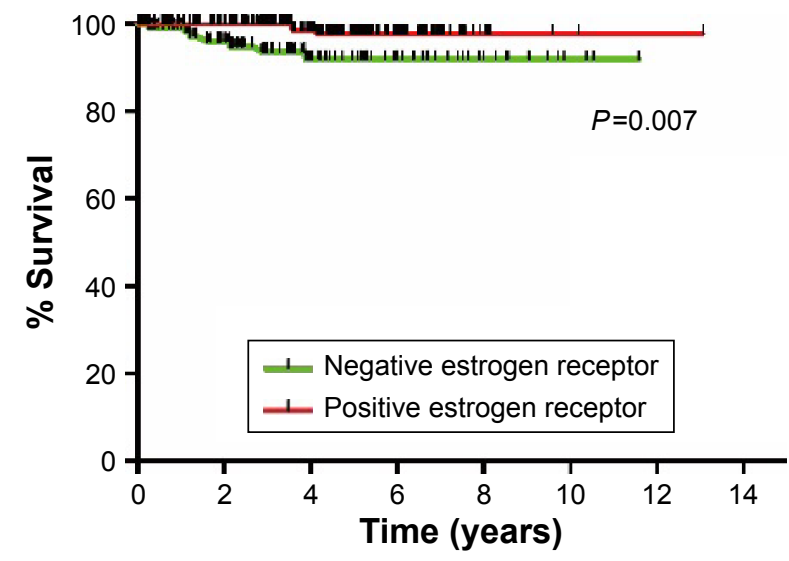

Figure I Kaplan-Meier local recurrence-free survival curve (different ER status). Abbreviation: ER, estrogen receptor. 


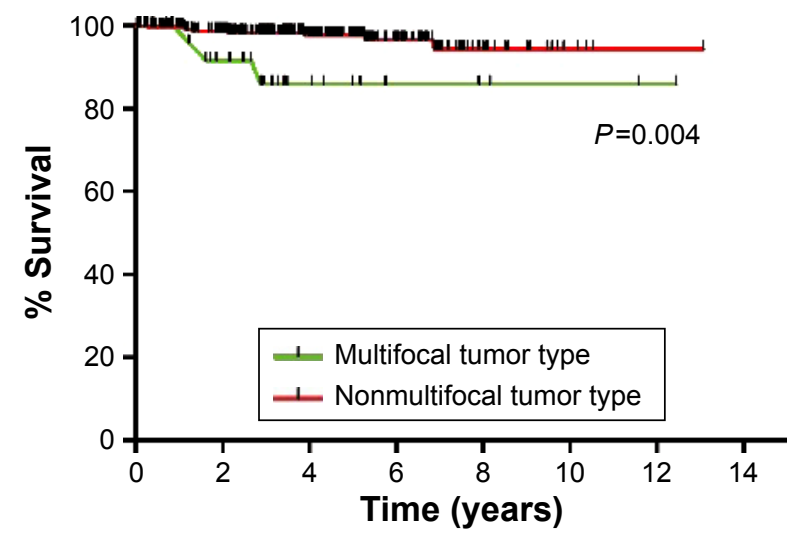

Figure 2 Kaplan-Meier local recurrence-free survival curve (different tumor types).

consisted of $397 \mathrm{BC}$ patients who underwent MST and ABR from January 1999 to December 2011 in our institution.

Based on the results of our study, we could confirm the oncological safety of BR following MST. After a median follow-up time of 3.6 years, which was well within the peak time of LR after MST reported by Crowe et al, ${ }^{15}$ the LR rate of ABR patients after MST was only 2.8\%. And this was also in line with analogous literature reporting that the rate of LR ranged from $2.3 \%{ }^{16}$ to $4.8 \%,{ }^{12}$ with at least 400 patients and a median follow-up time of 3 years.

All eleven LR cases that developed in our series were first detected by physical examination, and confirmed later with further imaging examinations and biopsies. This pattern of detection was exactly the same as several other studies, ${ }^{12,17,18}$ however, inconclusively, the gold standard for the diagnosis of LR remains needle cytology or excision biopsy. The outcome strongly confirmed the primary importance of physical examination in the surveillance of LR for this specific target population of patients undergoing post-MST ABR, even though mammography, ultrasound, and magnetic resonance imaging may have advantages over

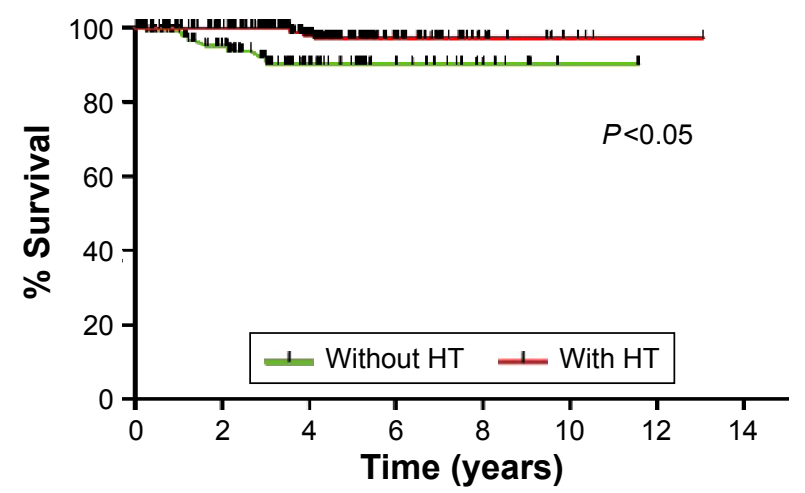

Figure 3 Kaplan-Meier local recurrence-free survival curve (with or without HT). Abbreviation: HT, hormonal therapy.

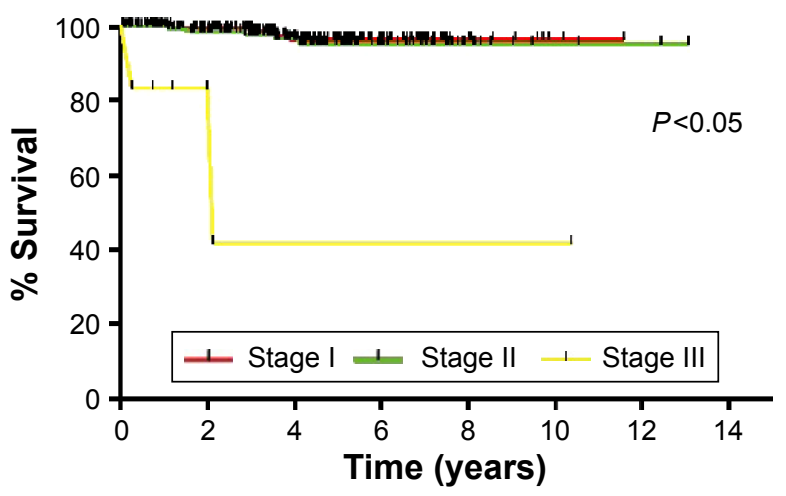

Figure 4 Kaplan-Meier local recurrence-free survival curve (different tumor stage).

physical examination under some circumstances. ${ }^{19-21}$ On the other hand, it implied that the presence of flaps didn't delay the detection of recurrent lesions, which was also consistent with conclusions in previous studies. ${ }^{6,14}$

In the univariate analysis, patients with positive PR, post-MST CT indeed obtained a higher 3-year LR-free survival than those without. The difference, however, was not statistically significant. It was possibly attributable to insufficient follow-up duration and limited number of recurrent events. However, a significant difference existed between patients with and without HT in both univariate $(P=0.007)$ and multivariate analysis $(P<0.05)$. The 3-year LR-free survival of patients with HT was $100.0 \%$ while it reached $92.0 \%$ without HT. It was obvious that the application of HT greatly contributed to lower rate of local recurrence in this specific population. Our study also demonstrated that tumor stage III was also one of the strongest prognostic factors of LR for ABR patients. Similarly, a study by Medina-Franco et al reported that tumor stage II or III, tumor size $>2 \mathrm{~cm}$, node-positive disease, and poor tumor differentiation were associated with higher LR rate. ${ }^{22}$ In a recent study, Kneubil et al also found that $\mathrm{BC}$ subtypes, body mass index, and tumor size were independent prognostic factors for risk of locoregional recurrence after immediate BR. ${ }^{23}$

The LR of BC after post-MST ABR might be attributed to inadequate resection, undetected multifocal tumors,

Table 3 Multivariate Cox regression analysis for risk factors and local recurrence

\begin{tabular}{llll}
\hline Risk factors & $\boldsymbol{P}$-value & OR & $\mathbf{9 5 \% ~ C l}$ \\
\hline Without HT vs with HT & $<0.05$ & 5.48 & $1.37-21.95$ \\
Stage III vs I & $<0.05$ & 51.82 & $6.71-400.15$ \\
vs II & $<0.05$ & 29.58 & $4.74-184.54$ \\
Tumor type & $<0.05$ & 7.45 & $1.97-28.21$ \\
multifocal vs nonmultifocal & & &
\end{tabular}

Abbreviations: $\mathrm{Cl}$, confidence interval; $\mathrm{HT}$, hormonal therapy; OR, odds ratio. 
or absence of postoperative radiation. Interestingly enough, it was noted in our study that the difference in terms of LRfree survival between multifocal and nonmultifocal tumor was indeed the most significant. With univariate analysis, the patients with multifocal tumor experienced a 3-year LR-free survival of $85.9 \%$ while 3-year LR-free survival increased to $99.0 \%$ for other patients $(P=0.004)$. Similarly, multivariate analysis also showed that with multifocal tumor, odds ratio was 7.45 (95\% confidence interval $=1.97$, 28.21) for LR-free survival probability compared with the nonmultifocal group. This finding might result in surgeons cautiously choosing to perform ABRs in some patients with multifocal $\mathrm{BC}$ preoperatively, who achieved higher incidence of LR $(8.3 \%)$ than patients with nonmultifocal BC (2.1\%) in our series. These patients were most likely the potential candidates for ABR and possibly not suitable for partial MST. However, whether it could apply to a larger population of patients needs further demonstration in a randomized controlled trial.

It deserves to be mentioned that only one patient presenting with LR received post-MST RT, indicating that remaining ten cases might not have received adequate local treatment, whereas most of these patients had no indications for RT according to guidelines now. If we accurately identified this highly selected BR patients with higher risk of LR, we might have had better local control over these patients. However, this still remains unclear now, which demands further investigation in the future.

LR in the setting of previous MST and ABR can pose a management challenge for clinicians, for there is no standard treatment for these patients at present. However, salvage treatment options include surgery, CT, RT, HT, and targeted therapy. And flap is removed according to surgeons' experience or intraoperative evaluation whether recurrent $\mathrm{BC}$ has invaded reconstructed breast.

The strength of our study included strict definition of LR and a wide range of ABRs, which is relatively new compared to previous studies. Furthermore, we found that multifocal tumor type was associated with higher LR rate after MST and ABR. The limitation included a limited number of patients with LR postoperatively, mixture of noninvasive and invasive breast carcinoma, the retrospective nature of the study, and loss of follow-up to some extent.

\section{Conclusion}

Post-MST, ABR is an oncologically safe procedure that does not compromise local control. Both univariate and multivariate analyses demonstrate that absence of HT, tumor stage III, and multifocal tumor type are associated with higher rate of LR after MST and ABR.

\section{Disclosure}

The authors report no conflicts of interest in this work.

\section{References}

1. Rosenqvist S, Sandelin K, Wickman M. Patients' psychological and cosmetic experience after immediate breast reconstruction. Eur J Surg Oncol. 1996;22(3):262-266.

2. Fernandez-Delgado J, Lopez-Pedraza MJ, Blasco JA, et al. Satisfaction with and psychological impact of immediate and deferred breast reconstruction. Ann Oncol. 2008;19(8):1430-1434.

3. Meretoja TJ, von Smitten KA, Leidenius MH, Svarvar C, Heikkila PS, Jahkola TA. Local recurrence of stage 1 and 2 breast cancer after skinsparing mastectomy and immediate breast reconstruction in a 15 -year series. Eur J Surg Oncol. 2007;33(10):1142-1145.

4. Lim W, Ko B, Kim H, et al. Oncological safety of skin sparing mastectomy followed by immediate reconstruction for locally advanced breast cancer. J Surg Oncol. 2010;102(1):39-42.

5. Styblo TM, Lewis MM, Carlson GW, et al. Immediate breast reconstruction for stage III breast cancer using transverse rectus abdominis musculocutaneous (TRAM) flap. Ann Surg Oncol. 1996;3(4):375-380.

6. Noone RB, Frazier TG, Noone GC, Blanchet NP, Murphy JB, Rose D. Recurrence of breast carcinoma following immediate reconstruction: a 13-year review. Plast Reconstr Surg. 1994;93(1):96-106, 107-108.

7. Romics LJ, Chew BK, Weiler-Mithoff E, et al. Ten-year follow-up of skin-sparing mastectomy followed by immediate breast reconstruction. Br J Surg. 2012;99(6):799-806.

8. Nedumpara T, Jonker L, Williams MR. Impact of immediate breast reconstruction on breast cancer recurrence and survival. Breast. 2011; 20(5):437-443.

9. Lindford AJ, Siponen ET, Jahkola TA, Leidenius MHK. Effect of delayed autologous breast reconstruction on breast cancer recurrence and survival. World J Surg. 2013;37(12):2872-2882.

10. McCarthy CM, Pusic AL, Sclafani L, et al. Breast cancer recurrence following Prosthetic, postmastectomy reconstruction: incidence, detection, and treatment. Plast Reconstr Surg. 2008;121(2):381-388.

11. Eriksen C, Frisell J, Wickman M, Lidbrink E, Krawiec K, Sandelin K. Immediate reconstruction with implants in women with invasive breast cancer does not affect oncological safety in a matched cohort study. Breast Cancer Res Treat. 2011;127(2):439-446.

12. Howard MA, Polo K, Pusic AL, et al. Breast cancer local recurrence after mastectomy and TRAM flap reconstruction: incidence and treatment options. Plast Reconst Surg. 2006;117(5):1381-1386.

13. Patterson SG, Teller P, Iyengar R, et al. Locoregional recurrence after mastectomy with immediate transverse rectus abdominis myocutaneous (TRAM) flap reconstruction. Ann Surg Oncol. 2012;19(8):2679-2684.

14. Lee TJ, Hur WJ, Kim EK, Ahn SH. Outcome of management of local recurrence after immediate transverse rectus abdominis myocutaneous flap breast reconstruction. Arch Plast Surg. 2012;39(4):376-383.

15. Crowe JJ, Gordon NH, Antunez AR, Shenk RR, Hubay CA, Shuck JM. Local-regional breast cancer recurrence following mastectomy. Arch Surg. 1991;126(4):429-432.

16. Langstein HN, Cheng MH, Singletary SE, et al. Breast cancer recurrence after immediate reconstruction: patterns and significance. Plast Reconstr Surg. 2003;111(2):712-720, 721-722.

17. Shaikh N, LaTrenta G, Swistel A, Osborne FM. Detection of recurrent breast cancer after TRAM flap reconstruction. Ann Plast Surg. 2001; 47(6):602-607.

18. Yoo H, Kim BH, Kim HH, Cha JH, Shin HJ, Lee TJ. Local recurrence of breast cancer in reconstructed breasts using TRAM flap after skin-sparing mastectomy: clinical and imaging features. Eur Radiol. 2014;24(9):2220-2226. 
19. Lindbichler F, Hoflehner H, Schmidt F, et al. Comparison of mammographic image quality in various methods of reconstructive breast surgery. Eur Radiol. 1996;6(6):925-928.

20. Edeiken BS, Fornage BD, Bedi DG, Sneige N, Parulekar SG, Pleasure J. Recurrence in Autogenous Myocutaneous Flap Reconstruction after Mastectomy for Primary Breast Cancer: US Diagnosis1. Radiology. 2003;227(2):542-548.

21. Destounis S, Morgan R, Arieno A, Seifert P, Somerville P, Murphy P. A review of breast imaging following mastectomy with or without reconstruction in an outpatient community center. Breast Cancer. 2011; 18(4):259-267.
22. Medina-Franco H, Vasconez LO, Fix RJ, et al. Factors associated with local recurrence after skin-sparing mastectomy and immediate breast reconstruction for invasive breast cancer. Ann Surg. 2002;235(6): 814-819.

23. Kneubil MC, Brollo J, Botteri E, et al. Breast cancer subtype approximations and locoregional recurrence after immediate breast reconstruction. Eur J Surg Oncol. 2013;39(3):260-265.

\section{Publish your work in this journal}

OncoTargets and Therapy is an international, peer-reviewed, open access journal focusing on the pathological basis of all cancers, potential targets for therapy and treatment protocols employed to improve the management of cancer patients. The journal also focuses on the impact of management programs and new therapeutic agents and protocols on

\section{Dovepress}

patient perspectives such as quality of life, adherence and satisfaction The manuscript management system is completely online and includes a very quick and fair peer-review system, which is all easy to use. Visit http://www.dovepress.com/testimonials.php to read real quotes from published authors. 